\section{LA-UR-03- 3153}

Approved for public release; distribution is unlimited.

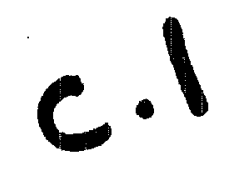

\author{
Titte: \\ RF SURFACE RESISTANCE OF \\ COPPER-ON-BERYLLIUM AT CRYOGENIC \\ TEMPERATURES MEASURED BY A 22-GHZ \\ DEMOUNTABLE CAVITY \\ Author(s): \\ Jianfei Liu, LANSCE-1 \\ Frank L. Krawczyk, LANSCE-1 \\ Sergey S. Kurennoy, LANSCE-1 \\ Dale L. Schrage, SNS-01 \\ Alan H. Shapiro, LANSCE-1 \\ Tsuyoshi Tajima, LANSCE-1 \\ Richard L. Wood, SNS-01 \\ Submitted to: \\ 2003 Particle Accelerator Conference (PAC2003) \\ Portland, Oregon \\ May 12-16,2003
}

Los Alamos National Laboratory, an affirmative action/equal opportunity employer, is operated by the University of California for the U.S. Department of Energy under contract W-7405-ENG-36. By acceptance of this article, the publisher recognizes that the U.S. Government retains a nonexclusive, royalty-free license to publish or reproduce the published form of this contribution, or to allow others to do so, for U.S. Government purposes. Los Alamos National Laboratory requests that the publisher identify this article as work performed under the auspices of the U.S. Department of Energy. Los Alamos National Laboratory strongly supports academic freedom and a researcher's right to publish; as an institution, however, the Laboratory does not endorse the viewpoint of a publication or g $\equiv$ tee its technical correctness. 


\title{
RF SURFACE RESISTANCE OF COPPER-ON-BERYLLIUM AT CRYOGENIC TEMPERATURES MEASURED BY A 22-GHZ DEMOUNTABLE CAVITY
}

\author{
J.-F. Liu ${ }^{\dagger}$, F. L. Krawczyk, S. S. Kurennoy, D. L. Schrage, A. H. Shapiro, T. Tajima, R. L. Wood, \\ Los Alamos National Laboratory, Los Alamos, NM 87545, USA
}

\section{Abstract}

A $22-\mathrm{GHz}$ demountable cavity on the cold head of a compact refrigerator system was used to measure the RF performance of several copper-plated Beryllium samples. The cavity inner surface was treated by chemical polishing and heat treatment, as well as an OFE copper coupon to provide a baseline for comparison. The measured surface resistance was reasonable and repeatable during either cooling or warming. Materials tested included four grades of Beryllium, OFE copper, alumina-dispersion strengthened copper (Glidcop $®$ ), and $\mathrm{Cu}$-plated versions of all of the above. Two coupons, $\mathrm{Cu}$ plated on Beryllium O-30 and I-70, offered comparable surface resistance to pure OFE copper or Cu-plated Glidcop. The RF surface resistance of $\mathrm{Cu}$-on-Beryllium samples at cryogenic temperatures is reported together with that of other reference materials.

\section{INTRODUCTION}

Beryllium material offers extremely low thermal expansion plus very high thermal conductivity at cryogenic temperatures. High-purity $\mathrm{Be}$ also has high electric bulk conductivity at cryogenic temperatures, which suggest that RF performance of bare Beryllium should be high. Past efforts to produce high-performance Be RF surface have failed to meet expectations, whereas measurements of copper on Be at cryogenic temperatures have proven effective. This attempt $[1,2]$ to produce $\mathrm{Cu}$ plated RF surfaces on Be substrate aims to combine the excellent bulk thermal properties of the Be substrate with the good RF properties of copper. If successful, this material should tolerate very high surface power densities and thus can be used in the production of high power RF cavities that do not exhibit thermal distortion. Work with small coupons was performed to allow confirmation of the desired RF performance and development of plating, fabrication, and brazing processes.

\section{EXPERIMENTAL SETUP}

The experimental setup is shown in Fig. 1. The cavity itself consists of two components: one is machined out of a block OFE copper, with a cylindrical cavity and a small annular groove on the flat end wall. The other is a replaceable endplate. The dimensions of the cavity are $20.138 \mathrm{~mm}$ diameter and $12.454 \mathrm{~mm}$ length. The detailed calculation of the cavity modes can be found elsewhere [3] and the typical values are as follows. At room temperature $\left(\rho=1.72 \times 10^{-8} \Omega \mathrm{m}\right)$, the working mode of the cavity is $\mathrm{TE}_{011}$ at $21.75 \mathrm{GHz}$, and the skin depth is $0.448 \mu \mathrm{m}$ for both $\mathrm{TE}_{011}$ and $\mathrm{TM}_{111}$. The groove serves to shift its frequency down from that in an exact pillbox, where $\mathrm{TE}_{011}$ mode would be degenerate with two $\mathrm{TM}_{111}$ modes. At the middle of the height, the cylinder has two RF ports with loop couplers made of a $50 \Omega$ coaxial line. The couplings are fixed around $1 \%$ at room temperature. $\mathrm{TM}_{111}$ modes are unexcited by adjusting the loop direction. The advantage of working with $\mathrm{TE}_{011}$ mode is that there is no surface current across the annular contact between the test coupon and the cylinder, so that the quality of the contact is not crucial.

The cavity was evacuated with a turbo-molecular pump station through four small holes of $2 \mathrm{~mm}$ diameter on the top surface. The typical vacuum was around $10^{-6}$ Torr before cooling down. The temperature of cavity was monitored with a silicon diode. The resonant frequency was defined as the frequency at which the transmitted power of the network analyzer took the maximum value of the $S_{21}$ coefficient in the scattering matrix. The quality factor $\mathrm{Q}_{\mathrm{L}}$ was determined through the half-power points of the $S_{21}$ coefficient. From the $S_{11}$ and $S_{22}$ coefficients, the coupling factors $\beta_{1}$ and $\beta_{2}$ were calculated. The cavity was placed on the cold head of a compact refrigerator system. The lowest temperature achieved was $\sim 12 \mathrm{~K}$. A LabView software was developed to automate the

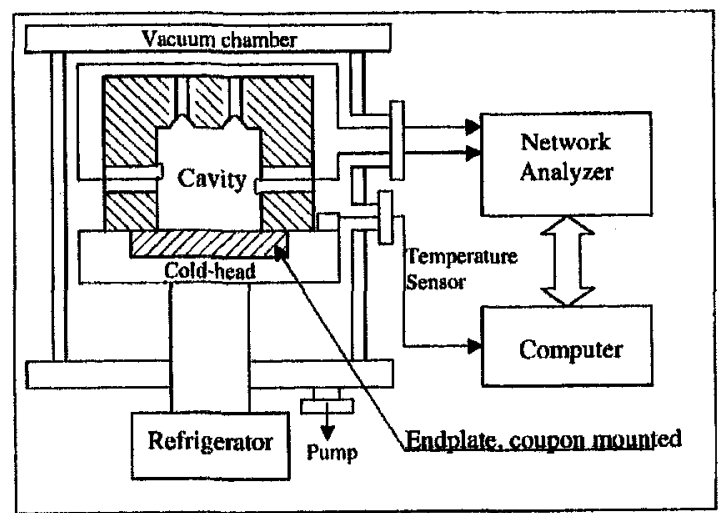

Figure 1: Schematic diagram of experimental setup with a $22 \mathrm{GHz}$ demountable cavity. The network analyzer automatically measured the transmission $S_{21}$ and the reflections $S_{11}$ and $S_{22}$ during either cooling down or warming up.

\footnotetext{
$\dagger_{\text {ifliu@lanl.gov }}$
} 
measurement, i.e., the unloaded quality factors $Q_{0}$ were obtained continuously during cooling down or warming up.

The cavity inner walls and one reference OFE copper coupon were chemically polished (CP) with a mixture of phosphoric acid $(85 \%)$, nitric acid $(69.8 \%)$ and acetic acid $(99.9 \%)$ in a volumetric ratio of $11: 4: 5$. They are then heat treated in a hydrogen furnace at $790{ }^{\circ} \mathrm{C}$ for a few minutes. The $\mathrm{Q}_{0, \mathrm{Cu}}(T)$, or, in the form of $\mathrm{R}_{\mathrm{s}, \mathrm{Cu}}(T)$, as a function of temperature was measured as reference for later comparison. Then the endplate was replaced by the various test coupons.

The surface resistance of the test coupons $\mathrm{R}_{\mathrm{s}, \mathrm{S}}(T)$ at temperature $T$ can be obtained from,

$$
\frac{R_{s, S}(T)}{R_{s, C u}(T)}=k\left(\frac{Q_{0, C u}(T)}{Q_{0, C u+S}(T)}-1\right)+1,
$$

where $k, 4.7737$, is the geometrical factor of the cavity.

\section{COUPON PREPARATION}

Four different grades of Beryllium substrate have been prepared, S-200FH, S-65, I-70, and 0-30. The primary differences between these grades were a) oxide content, and b) means of preparation of the "powder" from which the larger pieces were made (using HIP). For instance, the 0-30 was made from "spherical atomized" powder, and I-70 from "impact ground" powder. At least one coupon of each Be substrate candidate was given a $2.5-5$ $\mu \mathrm{m}$ thick "strike" of Nickel (diffusion barrier) and then plated 100-200 $\mathrm{mm}$ with high -purity copper. Bare Be coupons and copper-plated coupons were made from each of these substrate materials.

Table 1. A summary of coupons prepared for testing.

\begin{tabular}{|l|l|}
\hline Sample Ser.\# & \\
\hline C1 & $\begin{array}{l}\text { Pure OFE-copper, chemical polished } \\
\text { (CP) and heat treatment }\end{array}$ \\
\hline C2 & Pure OFE-copper \\
\hline S1 & Stainless steel 304 \\
\hline G1 & Cu-plated Glidcop \\
\hline G3 & Glidcop \\
\hline O-30SN1 & Cu-coated on Beryllium \\
\hline O-30SN3 & Bare beryllium \\
\hline I-70SN1 & Cu-coated on Beryllium \\
\hline I-70SN3 & Bare beryllium \\
\hline S-200FHSN1 & Cu-coated Beryllium \\
\hline S-200FHSN3 & Bare Beryllium \\
\hline S-65SN1 & Cu-coated Beryllium \\
\hline S-65SN3 & Bare Beryllium \\
\hline
\end{tabular}

For baseline comparison, we made coupons from a) 300-series stainless steel, b) OFE copper, and c) Glidcop with and without copper plating.

"OFE copper, ASTM F68 class 2 or better" is specified by LANL for hydrogen furnace brazed RF structures. The relevant factors were that it had to be $99.99 \%$ copper and less than 5ppm oxygen. The low-bulk oxygen content was necessary in order for the material to survive the brazing process without blistering. The hydrogen atmosphere is able to reduce oxides within a short distance of the copper surface without damage to the copper. Therefore, the plating probably does not need to meet the $<5$ ppm oxygen specification. Nonetheless, every effort was made to approach the $99.99 \%$ purity level in order to obtain acceptable RF surface resistance.

Two Glidcop coupons were prepared with and without copper plating, just for comparison. Cyanide-copper plating was used rather than the typical "bright-acid" type, since the former exhibits fewer problems in hydrogenfurnace brazing. The RF performance of cyanide-copper plating was previously unknown.

The details of the coupon fabrication are reported elsewhere [1]. All coupons we measured are listed in Table 1.

\section{RESULTS}

In order to calculate the RF surface resistance of the test coupons, the reference OFE copper endplate $\mathrm{Cl}$ was measured first. Figure 2 shows the $Q_{0}$ and $R_{s}$ in the function of temperature. The curves during cooling and warming were consistent with each other.

We repeated the measurement for each of the coupons, as shown in Fig. 3. The surface resistance for $\mathrm{Gl}$, Cuplated Glidcop, was comparable to that of OFE-copper C2 without chemical polishing and heat treatment.

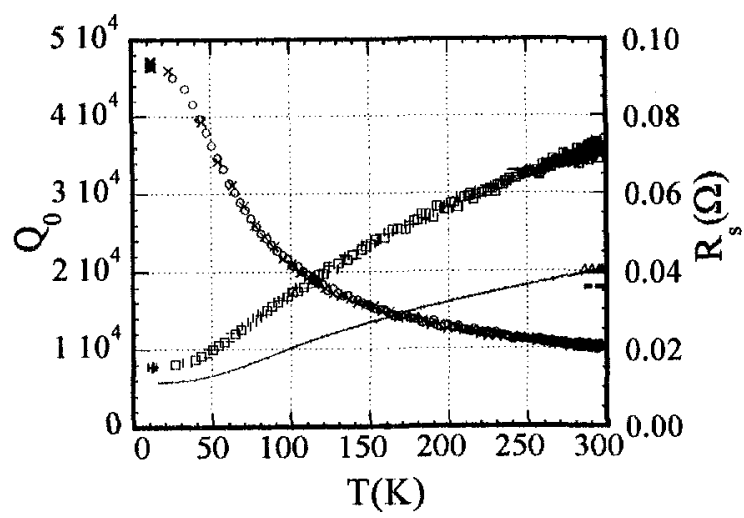

Figure 2. The unloaded quality factors $Q_{0}$ and the surface resistance $R_{s}$ of the reference OFE copper sample as a function of temperature. The crosses $(x)$ and circles (o) show the data during cooling down and warming up, respectively, and the corresponding $R_{s}$ are shown with plus $(+)$ and rectangular $(\square)$ markers. The solid line shows the surface resistance measured with a mirror-finished cavity at $13.6 \mathrm{GHz}$ [4] (the data is scaled to $21.75 \mathrm{GHz}$ by $\mathrm{f}^{1 / 2}$ law). The dashed line near the right vertical axis is the expected $Q_{0}$ by calculation, the corresponding surface resistance is indicated by the triangles $(\Delta)$. 


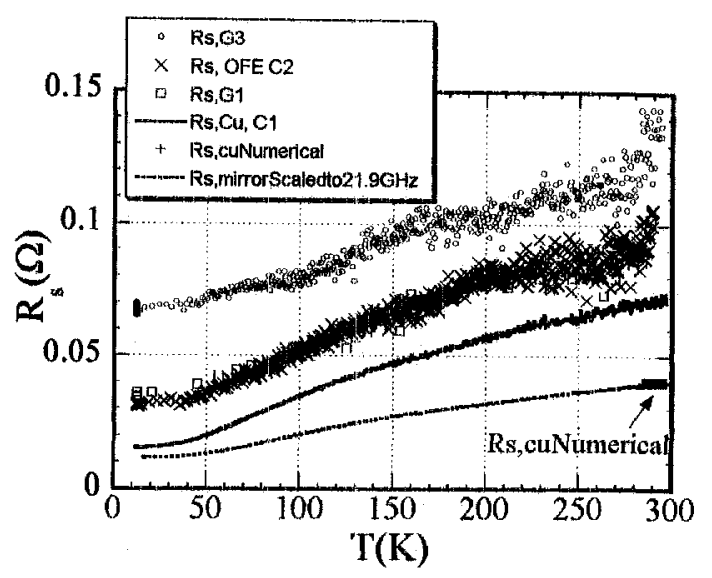

Figure 3. The $\mathrm{R}_{\mathrm{s}}$ for $\mathrm{C1}, \mathrm{C} 2, \mathrm{G} 1$, and $\mathrm{G} 2$ as a function of temperature together with data of a mirror-finished OFE copper measured elsewhere [4].

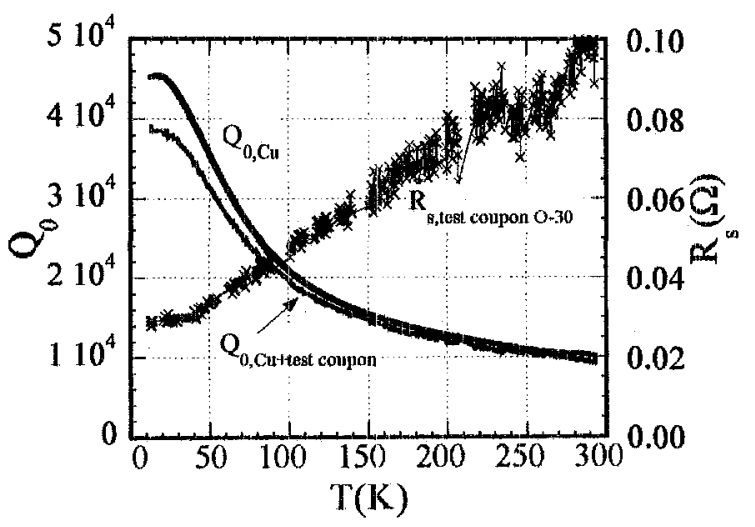

Figure 4. The $\mathrm{R}_{s}$ of the $\mathrm{Cu}$-plated on $\mathrm{O}-30$ Beryllium substrate as a function of temperature.

Four pairs of $\mathrm{Cu}$-plated $\mathrm{Be}$ and bare Be samples have been measured. One example is shown in Fig. 4. The test coupon is $\mathrm{Cu}$-plated on $\mathrm{O}-30 \mathrm{Be}$ substrate, and the surface resistance is comparable to OFE copper (C2) over the full temperature range. At $22 \mathrm{GHz}$, the RF skin depth is less than or equal to the oxide layer thickness on bare Beryllium. Thus, though we tried to measure the bare $\mathrm{Be}$ coupons, we were unable to measure the RF properties of metal Be. The measured $R_{s}$ were erratic and was much worse than the value that would be predicted from the $\mathrm{DC}$ electrical bulk resistivity.

\section{EFFECT OF SURFACE ROUGHNESS}

We found that the roughness of test coupons has a very significant effect at $22 \mathrm{GHz}$. The roughness of 8 coupons has been measured, and the average values are listed in Table 2. A typical value of RF skin depth for pure OFE copper at $22 \mathrm{GHz}$ is about $0.448 \mu \mathrm{m}$. Although the coupon C1 surface was treated very carefully with chemical polishing and heat treatment, its average roughness was still $0.163 \mu \mathrm{m}$, not small enough if compared to $0.448 \mu \mathrm{m}$ skin depth. This may explain why the unloaded quality factor was lower than the expected value.

Table. 2: Roughness and surface resistance of measured coupons.

\begin{tabular}{|l|c|c|c|}
\hline Sample Ser.\# & $\begin{array}{c}\text { Roughness } \\
\mathrm{R}_{\mathrm{a}}(\mu \mathrm{m})\end{array}$ & $\begin{array}{c}\mathrm{R}_{\mathrm{s}}(\Omega) \\
@ 72 \mathrm{~K}\end{array}$ & $\begin{array}{c}\mathrm{R}_{\mathrm{s}}(\Omega) \\
@ 293 \mathrm{~K}\end{array}$ \\
\hline C1 & 0.163 & 0.026 & 0.070 \\
\hline C2 & 0.83 & 0.043 & 0.100 \\
\hline S1 & & 0.347 & 0.388 \\
\hline G1 & 0.586 & 0.044 & 0.096 \\
\hline G3 & 0.155 & 0.078 & 0.133 \\
\hline O-30SN1 & 0.632 & 0.041 & 0.101 \\
\hline I-70SN1 & 1.238 & 0.042 & 0.109 \\
\hline S-200FHSN1 & 0.988 & 0.087 & 0.208 \\
\hline S-65SN1 & 0.644 & 0.168 & 0.287 \\
\hline
\end{tabular}

The roughness of $\mathrm{C} 2$ was much worse than $\mathrm{C} 1$. It was clearly shown that the chemical polishing and heat treatment were effective to improve the surface roughness.

\section{SUMMARY}

The RF surface resistance as a function of temperature down to $\sim 12 \mathrm{~K}$ was measured using a $22-\mathrm{GHz} \mathrm{TE}_{011}$ mode cavity.

Among four $\mathrm{Cu}$-plated $\mathrm{Be}$ coupons, two coupons $\mathrm{Cu}-$ plated on $\mathrm{Be} \mathrm{O}-30$ and $\mathrm{I}-70$ showed a comparable $\mathrm{RF}$ performance to that of the pure OFE copper and the copper-plated Glidcop over the full temperature range. The "cyanide copper" plating method was shown to be acceptable.

Our next step is to perform heat treatment of the copper-plated $\mathrm{Be}$ coupons to investigate the stability and $\mathrm{RF}$ performance degradation caused by $\mathrm{Be} / \mathrm{Cu}$ diffusion during braze heat.

\section{ACKNOWLEDGEMENT}

We would like to express our thanks to Lloyd Young for his comments and discussion, to ETL for machining of the cavity and heat treatment, and to Randy Edwards for the cavity chemical polishing.

\section{REFERENCES}

[1] R. Wood, Memo LANSCE-1:02-058, August 2002.

[2] D. Schrage, Memo AT-1:91-384, September 1991.

[3] S. Kurennoy, Memo LANSCE-1:02-042, September 2002.

[4] J.-F. Liu, J. Appl. Phys. 87, 3912, (2000). 